\title{
David STEPHENSON, Medieval Powys: Kingdom, Principality and Lordships, 1132-1293
}

\section{Amaury Chauou}

\section{(2) OpenEdition}

\section{Journals}

Édition électronique

URL : https://journals.openedition.org/ccm/8224

DOI : $10.4000 / \mathrm{ccm} .8224$

ISSN : 2119-1026

\section{Éditeur}

Centre d'études supérieures de civilisation médiévale/Université de Poitiers

\section{Édition imprimée}

Date de publication : 1 septembre 2021

Pagination : 298-299

ISBN : 978-2-490783-10-6

ISSN : 0007-9731

\section{Référence électronique}

Amaury Chauou, «David stephenson, Medieval Powys: Kingdom, Principality and Lordships, 1732-1293» Cahiers de civilisation médiévale [En ligne], 255 | 2021, mis en ligne le 01 septembre 2021, consulté le 05 février 2022. URL : http://journals.openedition.org/ccm/8224; DOI : https://doi.org/10.4000/ccm. 8224

\section{(c) (i) (9)}

La revue Cahiers de civilisation médiévale est mise à disposition selon les termes de la Licence Creative Commons Attribution - Pas d'Utilisation Commerciale - Pas de Modification 4.0 International. 
David StePhenson, Medieval Powys: Kingdom, Principality and Lordships, 1132-1293, Woodbridge, Boydell Press (Studies in Celtic History, 35), 2016.

Au sein d'une historiographie galloise longtemps teintée de nationalisme, cette monographie de David Stephenson est à marquer d'une pierre blanche. Dès avant 1914, les hautes figures de John Edward Lloyd et d'Owen Morgan Edwards, proches du mouvement politique du Cymru Fydd ( « Jeune Galles »), ont en effet posé pour des décennies les bases d'une historiographie mêlant une chronologie, une géographie et un catalogue de la résistance anti-anglaise en terre galloise, faisant la part belle aux temps médiévaux. Dans ce paradigme présenté pour d'autres contrées par Benedict Anderson, le moteur de la construction nationaliste galloise résidait dans la maison des princes de Gwynedd, la seule en mesure d'influencer les deux autres principautés galloises (le Powys, au centre, et le Deheubarth, au sud), et d'incarner l'unité face à la conquête et à la domination du puissant voisin anglais. La révolution copernicienne qu'effectue l'a. renverse complètement cette perspective en appelant dès l'introduction à réviser fondamentalement l'approche de l'histoire du Pays de Galles médiéval (p. 20) et en mettant l'accent sur le royaume du Powys, désormais considéré pour lui-même et non plus comme l'indéfectible allié des menées anglaises dans la péninsule galloise.

Déconstruire les biais d'une histoire régionaliste favorable au Gwynedd pour mieux analyser les relations seigneuriales et la gouvernance d'un Powys trop longtemps négligé est d'autant plus à la portée de $\mathrm{D}$. Stephenson qu'il a déjà consacré une monographie au Gwynedd du XIII ${ }^{\mathrm{e}} \mathrm{s}$. vu sous l'angle des pouvoirs politiques. On retrouve logiquement derrière la présente étude sur le Powys - en moins riche le même corpus documentaire que pour l'influente principauté voisine : des chroniques (en latin et en vernaculaire), des écrits de Giraud de Barri, des actes princiers, des cartulaires monastiques, des apports venus de la généalogie et de l'histoire du droit, des sources issues de la chancellerie et de l'Échiquier d'Angleterre, auxquels s'ajoutent les données de la littérature cymrique en moyen-gallois et celles de l'archéologie.

L'ouvrage s'articule en deux parties. Dans un premier temps est développée une approche narrative de l'histoire du Powys. Le chap. 1 reprend le dossier de l'existence d'un royaume du Powys aux environs de l'an Mil pour en décaler l'apparition durant les premières décennies $d u \mathrm{XII}^{\mathrm{e}} \mathrm{s}$. Les grandes lignes de l'œuvre fondatrice que Maredudd ap Bleddyn († 1132) laisse à son fils Madog ap Maredudd
$(† 1160)$ sont fermement établies. Au moment où le pouvoir d'Henri I ${ }^{\text {er }}$ Beauclerc menace les marges orientales de la péninsule, la nécessité du dialogue avec le maître de Westminster se fait déjà sentir, de même que la méfiance du Powys vis-à-vis du Gwynedd. Les chap. 2 à 5 retracent le règne de consolidation de Madog ap Maredudd ("The Age of Eminence »), puis l'affaissement du Powys en raison des luttes dynastiques, alors qu'à la veille des années 1160 il avait tout pour coexister sereinement avec l'« empire Plantagenêt ». La fragmentation dynastique du Powys contraste jusqu'au cœur du $\mathrm{XIII}^{\mathrm{e}} \mathrm{S}$. avec la prise d'ascendant puis la suprématie du Gwynedd. Surtout, l'unité de la principauté semble irrémédiablement écartelée entre une zone sud, aux mains de Gwenwynwyn ( $†$ 1216) puis de ses héritiers, qui ne s'envisagent plus autrement que comme les équivalents gallois des barons anglais de la Marche, et une zone nord où ne subsistent que des pouvoirs seigneuriaux très dégradés par rapport aux anciennes prérogatives princières. L'a. tisse un lien fécond entre ces évolutions divergentes et un certain niveau de soumission au Gwynedd, parallèle à des pratiques d'accommodement avec les barons de la Marche dont les plus visibles sont les intermariages. Les chap. 6 à 8 referment cette narration en éclairant comment les potentats locaux du Nord- et du Sud-Powys mettent à profit l'ingérence du gouvernement d'Henri III dans les affaires galloises puis survivent au sein du nouvel ordre imposé militairement par Édouard I ${ }^{\text {er }}$ dans le statut de Rhuddlan (1284), alors que la domination du Gwynedd s'est évanouie avec la mort de Llywelynn ap Gruffydd (1282).

Un deuxième volet reprend thématiquement la matière étudiée en centrant successivement sur la gouvernance du Powys (chap. 9), les dynamiques séculières entre fragmentation et intégration (chap. 10), la dimension ecclésiastique (chap. 11), et enfin, dans un chapitre conclusif, sur l'imaginaire géopolitique du Powys en termes de peurs et d'aspirations (chap. 12). D. Stephenson y gratifie le lecteur de nouvelles vues pénétrantes sur le plan de l'histoire des élites, ou de celle du genre. Surtout, cette deuxième section rééquilibre avec bonheur les tendances parfois très focalisées sur le Gwynedd que comporte toute présentation du Pays de Galles médiéval, en partant avant tout du point de vue « powysien».

L'ensemble, touffu au point de pouvoir dérouter quiconque n'est pas familier des subtilités généalogiques, géographiques ou institutionnelles des temps 
médiévaux au Pays de Galles, aurait pu être davantage soutenu par un effort sur les cartes (qui apparaissent bien pauvres) et sur les annexes (les arbres généalogiques ne sont pas suffisants). En particulier, une chronologie des presque deux siècles étudiés aurait été bienvenue. En outre, on regrette que des perspectives comparatistes entre le Powys et d'autres principautés des marges de l'Occident médiéval n'aient pas été tracées au sein d'une vraie conclusion sur les concepts mêmes de pouvoirs princiers et de domination territoriale. Certaines originalités galloises n'en seraient que mieux ressorties en termes de gouvernance. Mais telle quelle, la moisson est déjà substantielle en ce qu'elle ne participe d'aucune construction téléologique de l'histoire galloise. Ce constat ne rend que plus désirable désormais le même type de monographie sur la troisième principauté galloise de l'époque : le Deheubarth.

Amaury CHaUOU

EA 4451 - Centre de recherche bretonne et celtique / Université de Bretagne Occidentale 